\section{Cuerpos y feminidades en la vida religiosa en el Instituto de Hijas de Maria en Colombia (1980-2015)}

\section{Bodies and Femininities in Religious Life in the Instituto de Hijas de Maria in Colombia (1980-2015)}

Corpos e feminidades na vida religiosa no Instituto de Hijas de Maria, na Colômbia (1980-2015)

\section{Pablo A. Scharagrodsky* \\ Carolina M. Ojeda**}

* Doctor en Ciencias Sociales y Humanas de la Universidad Nacional de Quilmes. Docente investigador de la Universidad Nacional de Quilmes y de la Universidad Nacional de la Plata. Correo electrónico: pas@unq.edu.ar

** Magíster en Educación de la Universidad Pedagógica, Colombia. Doctoranda en Ciencias de la Educación de la Universidad de la Plata. Correo electrónico: carolina.ojeda.rincon@gmail.com

\section{Resumen}

Los trabajos históricos referidos a la vida conventual y religiosa en América Latina se focalizan en su mayoría en periodos como la Colonia y en procesos como la labor educativa de niñas y jóvenes en todo el continente. A pesar de una significativa producción investigativa en torno al tema, no es fácil acceder a trabajos de historia reciente sobre la vida conventual o las instituciones religiosas femeninas. En este artículo se exponen algunas reflexiones en torno a la producción de cuerpos y feminidades en los espacios de formación destinados para mujeres del Instituto de las Hijas de María-Religiosas de las Escuelas Pías, que arribaron a Colombia en la segunda mitad de siglo xx. Las fuentes de consulta fueron documentos institucionales y materiales educativos y pedagógicos utilizados en su proceso de formación.

\section{Palabras clave}

Cuerpos; feminidades; vida religiosa femenina; Hijas de María-Religiosas de las Escuelas Pías

\section{Abstract}

The historical works related to convent and religious life in Latin America are mostly focused in periods like the Colony and in processes such as the educational role of girls and young females across the continent. Despite the significant research on the subject, it is not easy to access recent history works about convent life and women's religious institutions. In this article, the authors present some reflections on the production of bodies and femininities in the spaces for women training in the Institute of the Daughters of Mary-Religious of the Pious Schools, who arrived in Colombia in the second half of the twentieth century. The reference sources consulted were institutional documents and educational and teaching materials used in the education process.

\section{Keywords}

Bodies; femininities; female religious life; Daughters of Mary-Religious of the Pious Schools

\section{Resumo}

Os trabalhos históricos relativos à vida conventual e religiosa na América Latina focalizam-se, na sua maioria, no período colonial e em processos tais como o trabalho educativo de crianças e jovens no continente todo. Apesar de uma significativa produção investigativa sobre o tema, não é fácil acessar trabalhos de história recente sobre a vida conventual ou das instituições religiosas femininas. Neste artigo se expõem algumas reflexões em torno da produção de corpos e feminidades nos espaços destinados à formação de mulheres do Instituto das Filhas de Maria-religiosas das Escolas Pías que chegaram na Colômbia, na segunda metade do século Xx. As fontes consultadas foram documentos institucionais e materiais educativos e pedagógicos utilizados no seu processo de formação.

\section{Palavras-chave}

Corpos; feminidade; Instituto das Filhas de Maria-religiosas das Escolas Pías

Fecha de recepción: febrero 25 de 2016

Fecha de aprobación: abril 16 de 2016

................................................ 


\section{Introducción}

$\mathrm{L}$ os trabajos históricos sobre monjas y beatas así como los diferentes espacios (conventos, claustros, beaterios, etc.) referidos a la vida religiosa han estado fuertemente vinculados en términos analíticos con el campo de la historia de las mujeres, el cual, posteriormente, se enriqueció de la historia sociocultural, el giro lingüístico y los estudios feministas y de género. Estos últimos introdujeron nuevas preguntas a partir de problematizar lo que se definió inicialmente como lo femenino, ofreciendo categorías analíticas y herramientas metodológicas con que se des-universalizaron y se des-esencializaron conceptos como la mujer, la familia, el patriarcado o lo doméstico. Lo anterior trajo consigo una diversidad de objetos de estudio, temporalidades, fuentes documentales, así como temas y problemas de investigación para abordarlos desde una perspectiva histórica y feminista, lo que provocó apuestas cada vez más osadas tanto teórica como historiográficamente, que hicieron de estos estudios un campo fascinante de incursión e interrogación.

Como historiadores de la educación nos ha interesado indagar por el papel que cumplen las instituciones educativas en la producción y reproducción de cuerpos generizados. Muy interpelados también por la historia de las mujeres, las fuentes documentales nos han situado frente a unos sujetos encargados de la tarea educativa, quienes suplieron durante años el papel del Estado en la estrategia de regulación y control que supuso el proyecto de escolarización en tierras americanas: las monjas y hermanas de congregaciones religiosas femeninas, cuya presencia en países como Colombia desbordó ampliamente un propósito meramente evangelizador, y que tuvieron un papel central en la formación de subjetividades generizadas ${ }^{1}$.

Atendiendo a ello quisimos adentrarnos en una comunidad religiosa femenina, el Instituto de las Hijas de María-Religiosas de las Escuelas Pías, la cual desde su fundación en España en el siglo XIX tuvo como consigna promover a la mujer bajo la estrategia de la educación y a través de esta, la evangelización. Nuestro objetivo ha sido analizar los procesos que construyen los cuerpos femeninos religiosos desde la perspectiva crítica de género y el análisis crítico del discurso, tomando como fuentes documentos institucionales de la Congregación, directrices emitidas por la Santa Sede en el Vaticano y material

1 Pese a la importancia señalada, estos sujetos quedaron, en parte, al margen de la investigación en historia de la educación y la pedagogía en Colombia, quizás porque prevaleció la mirada sobre el proyecto educativo estatal. educativo utilizado en el proceso de formación de las novicias. Ambos enfoques teórico-metodológicos nos permitieron historizar el devenir permanente de los cuerpos femeninos (Scott, 2011) y, al mismo tiempo, atender al contexto de producción de los discursos religiosos (Fairclough, 1992) y sus re-semantizaciones.

Si bien la llegada de la congregación a la ciudad de Bogotá fue en 1953 y diez años después se fundó el primer noviciado femenino escolapio, para nuestro análisis nos situamos en la década de los ochenta por presentar un momento de discontinuidad en los modos de conceptualizar a las mujeres, que contribuyó a construir un cierto tipo de feminidad adecuada, deseable, correcta y posible. Lo anterior introdujo cambios en el proceso de formación en la vida religiosa, que para el caso de las Escolapias también comprende un quehacer pedagógico. En este sentido los interrogantes planteados en el presente trabajo se condensan de la siguiente manera: ¿Qué feminidad se produjo en las últimas tres décadas en el proceso de formación en la vida religiosa? ¿A través de qué técnicas corporales se llegó - y llega—a ser una religiosa escolapia?

Al suponer que toda educación pasa necesariamente por el cuerpo, nos encontramos con un conjunto de técnicas corporales (Le Breton, 2002; Mauss, 1979; Preciado, 2014) que tienen como propósito disciplinar, regular y gestionar el cuerpo de quien aspira a la vida religiosa. Este, desde su ingreso a la institución, es comprendido a través de un marco de inteligibilidad que lo engeneriza, asignándole gestos, posturas, desplazamientos, movimientos, comportamientos, proxemias, a través de la ejecución reiterativa de una serie de prácticas normativas, que tienen como resultado producir un sujeto singular: la religiosa escolapia, cuyo proceso de apropiación subjetiva da como resultado la materialización de un yo corporal. Estas normas y prácticas reguladoras surgen en marcos históricos y culturales que preceden y a su vez son las que permiten la formación de un sujeto, quiere decir que el yo nunca preexiste sino que acontece, se hace carne (Butler, 2010).

En esta misma línea, partimos del supuesto de que es imposible pensar los cuerpos, las feminidades, las sexualidades y los deseos por fuera de un entramado entre instituciones, cultura, lenguaje, relaciones de poder y de dominación, imaginarios, representaciones, prácticas, saberes y discursos (Butler, 2001; Corbin, Courtine y Vigarello, 2005; Turner, 1989). Cuando nos preguntamos por cómo ciertas instituciones (en este caso las vinculadas con Escuelas Pías) y determinadas prácticas y técnicas 
produjeron el fenómeno al que hicieron permanente alusión: los cuerpos femeninos (Butler, 2010; Scott, 2011), atendemos a una concepción del cuerpo como contingencia, como probabilidad, para reconocerle su carácter inestable, perspectivo, cuya producción nunca cesa.

Para mostrar el análisis estructuramos el texto en dos partes. En la primera contextualizamos la llegada de las Hermanas ${ }^{2}$ Escolapias a Colombia, los inicios de su labor educativa con la comunidad y el tipo de formación de mujeres religiosas. En la segunda, analizamos el proceso por el cual se deviene en mujer religiosa en la congregación escolapia, centrando la atención analítica en las técnicas corporales y los modos de producción de las mismas.

\section{La congregación de las madres escolapias y su arribo a Colombia}

Paula Montal Fornés, nacida en 1799 en Arenys de Mar (Barcelona), fue la fundadora del Instituto de las Hijas de María-Religiosas de las Escuelas Pías (Escolapias). Beatificada en el año de 1993 y proclamada santa en 2001, es reconocida por la apertura de escuelas pías para niñas en el siglo XIX en España, acogiendo la obra de San José de Calasanz. De ella se destaca en los documentos institucionales su fuerte interés porque las niñas tuvieran el acceso a la educación que era exclusivo para los varones. De allí que sea definida por las escolapias como "profeta de la mujer".

La educación impartida en estas escuelas buscaba "salvar las familias enseñando a las niñas el santo temor de Dios" (Madres escolapias, 1983, p. 8), expresado en una enseñanza cristiana, "preparando a las alumnas para desempeñar su puesto en la familia, agente de evangelización y responsable del bien de la sociedad" (p. 12). Por ello su misión educadora, considerada un cuarto voto, articula la formación en la fe y en las primeras letras, que se recoge en el lema calasancio "Piedad y Letras".

2 La diferencia en los términos monja y hermana responde a diversos aspectos, como la historicidad, la traducción, el uso social, entre otros. En este escrito nos referimos a mujeres de vida religiosa y atendemos la explicación ofrecida en la congregación Escolapia, quienes aunque por tradición se denominan Madres, se reconocen como hermanas por vivir la vocación desde el servicio a comunidades, diferenciándose de las monjas quienes viven la experiencia religiosa de manera contemplativa y de oración generalmente en claustros y monasterios.
El legado de su fundadora y la guía para la labor religiosa y social de la congregación se recoge en las "Constituciones de las Hijas de María dedicadas a la enseñanza de las niñas" de 1853, documento aprobado por el papa Pío IX en 1860. Allí se encuentra la adaptación que hace Montal de las reglas del fundador, y aparecen de manera detallada la organización, los modos de vida en comunidad, las responsabilidades, las sanciones, los criterios de ingreso o exclusión y demás aspectos referidos al funcionamiento de la congregación. Hasta el día de hoy, estas reglas son revisadas y actualizadas cada cierto tiempo con el fin de responder a las realidades sociales y espirituales de cada comunidad y momento histórico.

A comienzos de siglo xx la congregación inició su expansión hacia lo que el catolicismo llamó "El continente de la esperanza". Llegó inicialmente a Cuba en 1911 (de allí fueron expulsadas en 1961 y regresaron en 1992), Argentina en 1931 (se ubicaron primero en Córdoba y luego en otras provincias), Brasil en 1933, Chile en 1953, Colombia en 1954 (ubicadas en Bogotá y Medellín), México en 1970, República Dominicana en 1984, Ecuador en 1990 (Alegre, Albiñana, Costanera, Labarta, Micip y Pérez, 2008) ${ }^{3}$. Su llegada a cada país se iniciaba con la fundación de escuelas y posteriormente de noviciados y casas congregacionales.

En 1954 se instalaron primero en el centro de Bogotá con una matrícula escasa, mientras que en Medellín para 1960 contaban con 180 niñas de un sector de clase media con presencia de fincas de grandes extensiones y que para la época apenas se anunciaba como uno de los primeros centros de urbanización, tras la industrialización de la ciudad de primera mitad de siglo xx. Con el apoyo económico de los hermanos escolapios, quienes arribaron a Colombia en la década de los 40 con el propósito de fundar escuelas y formar vocaciones, ambas comunidades continuaron con la apertura de escuelas masculinas, femeninas y mixtas en los dos departamentos, en sectores de medianos y escasos recursos. En 1963 fundaron el primer noviciado femenino escolapio de Colombia en una zona aledaña a la capital conocida como "Yerbabuena", de gran valor histórico desde la época de la Colonia y donde hoy habitan tanto campesinos como miembros de familias prestigiosas y adineradas de Bogotá.

La formación de novicias, en esta como en otras congregaciones religiosas de actividad apostólica, acogió las directrices emitidas por el Concilio Vati-

3 También llegaron a Asia y África: Japón en 1952, Filipinas en 1983, Senegal en 1966, Guinea Ecuatorial en 1980, Guinea Bissau en 1986. 
cano II, realizado entre 1962 y 1965, y que se convirtió en el escenario donde tuvo lugar una de las reformas más importantes que ha sufrido la Iglesia católica. En él se abordaron diversidad de temas institucionales y misionales, entre estos todo lo concerniente a la vida religiosa ${ }^{4}$ :

La adecuada adaptación y renovación de la vida religiosa comprende a la vez el continuo retorno a las fuentes de toda vida cristiana y a la inspiración originaria de los Institutos, y la acomodación de los mismos, a las cambiadas condiciones de los tiempos. (Perfectae Caritatis, 1965)

Se animó entonces a renovar tanto las leyes y la organización interna de las congregaciones, como los procesos de formación y labor de apostolado, desechando prácticas que resultaran anticuadas.

Uno de los principios rectores de esta renovación fue el fortalecimiento en la identificación con las fundadoras(es) y sus legados, por ello, un tema de especial atención fue precisamente la promoción de la mujer. En un documento que recoge las cuestiones centrales abordadas en el Concilio con relación a la misión evangelizadora de las congregaciones, se destaca:

La promoción de la mujer, uno de los signos de los tiempos según el Papa Juan XXIII, ha tenido no pocas resonancias en la vida de las comunidades cristianas de diversos países. Aun cuando en algunas regiones el influjo de corrientes extremistas del feminismo está condicionando profundamente la vida religiosa, casi en todas partes las comunidades religiosas femeninas están en una búsqueda positiva de formas de vida común más idóneas para la renovada conciencia de la identidad, de la dignidad y de la misión de la mujer en la sociedad, en la Iglesia y en la vida religiosa. (Congregación para los Institutos de Vida Consagrada y las Sociedades de Vida Apostólica, 1994)

No es un dato menor que otras congregaciones también provenientes de Europa tuvieron como objeto de intervención a las mujeres y, ubicándose en sectores populares de Bogotá y Medellín, se encargaron de obligaciones del Estado poco atendidas, como la alfabetización o la capacitación en oficios. Si bien estos últimos no escaparon de la naturalización de una división sexual del trabajo, para muchas muje-

4 Las reformas a la vida consagrada previstas en el Concilio se recogen además del Decreto Perfectae Caritatis del 28 de octubre de 1965, en la constitución dogmática Lumen Gentium, los números dedicados a la vida religiosa y el motu proprio Ecclesiam suam. Estos dieron las premisas para los posteriores documentos emitidos y son referentes para la actualización de lineamientos y decisiones en los institutos religiosos. res significó la emancipación de hogares que eran núcleos de violencia, opresión o pobreza y hasta la posibilidad de considerar asuntos como la planificación familiar como una opción en sus vidas (Jiménez, 2015). Como sugiere Ramírez (2003) el actuar de las congregaciones no puede ser leído únicamente bajo el lente evangelizador, sino también como un actuar de agencia por y para mujeres:

Los conventos y los monasterios, además de ser lugares de recogimiento y de dedicación a la vida espiritual, permitieron a las religiosas participar en proyectos colectivos orientados a la educación de las niñas y las jóvenes y a las acciones asistenciales como formas de mediación de las mujeres ante la miseria y el sufrimiento humano. (p. 153)

La vida religiosa empieza con un llamado de Dios, cuya invitación a responder implica formarse para cumplir con la misión encomendada. Para el caso de las Hijas de María, su misión se encuentra en tres instancias: formación integral de la infancia y la juventud, promoción de la mujer y atención a las familias. La formación es un proceso gradual y progresivo, con un intenso trabajo personal que está acompañado siempre por una formadora y a su vez la participación de las otras religiosas con quienes se convive. Las estrategias educativas y pedagógicas utilizadas, así como los principios fundamentadores que la sostienen, son adaptadas a las realidades sociales y espirituales de cada comunidad y momento histórico, en relación con las directrices emitidas por El Vaticano y otras dependencias regulatorias a nivel local y regional. Este proceso inicia en el aspirantado, que tiene una duración de entre seis meses y un año; luego viene el prenoviciado, con duración de entre seis meses y dos años, periodo que consiste en que la aspirante profundice en su vocación y clarifique las razones de su opción. El siguiente paso es el noviciado de dos años, donde se inicia la vida religiosa que se centra en sumarse a las exigencias de la congregación, el instituto en que se inscribe y se asume la decisión de optar por una vocación; el juniorado es la primera instancia a la profesión, que puede durar entre cinco y nueve años, y de ahí en adelante la profesión donde se asumen los votos perpetuos (Madres escolapias, 1983; Alegre, Sesma, Armenda y Costa-Jusa 1983).

El rasgo educador las diferenciaba de otras congregaciones, para ello su admisión presentaba dos modalidades: estaban quienes sin haber terminado el bachillerato iniciaban su formación religiosa y al mismo tiempo finalizaban sus estudios y quienes ya siendo bachilleres entraban a profesionalizarse en escuelas normales o la universidad, para responder a su actuar misional con la educación de niñas, que las 
llevaba a asumir el rol de maestras de escuela 5 . Esto a su vez sugiere el desarrollo de tres dimensiones en el proceso de formación -entendido como un proceso específico, personalizado y permanente- que cualifica para la vida en comunidad y para ejercer su misión educativa: humana, espiritual y carismática. La primera se focaliza en el trabajo de autoconocimiento, como método para favorecer la relación consigo misma y con los otros, sean alumnas o compañeras de comunidad, y se traduce en una serie de técnicas que, como veremos, definen y estabilizan unos modos de saberse y hacerse mujeres como condición para asumir el compromiso vocacional. La segunda dimensión hace referencia a la vida consagrada, caracterizada por la vivencia de los votos de castidad, pobreza, obediencia, en el marco del voto específico de la misión educadora de la iglesia y la Virgen María, figura que también adquiere un importante protagonismo desde el Concilio, como modelo de entrega, escucha, fidelidad, colaboradora de la voluntad de Dios y salvadora de la familia. La dimensión carismática reúne un conjunto de técnicas a través de las cuales se adquieren conocimientos relacionados con la misión congregacional, la enseñanza y las problemáticas sociales a intervenir como mujeres educadoras de la Iglesia (Alegre et al., 1983, Congregación General, 2015).

Asentada y consolidada la congregación religiosa de las Escuelas Pías en Colombia, ¿qué tipo de feminidad se contribuyó a construir? ¿Cuáles fueron sus mandatos e ideales ficcionales dominantes? ¿A partir de qué prácticas y técnicas se produjo el cuerpo femenino religioso? y ¿qué ideales ficcionales femeninos provenientes del discurso religioso quedaron excluidos, silenciados u omitidos?

\section{Las hijas de María: esposas y vírgenes consagradas}

Un ideal regulatorio de feminidad habita el convento de las Hijas de María representado en dos figuras de mujeres: las madres, que son a su vez esposas, y las mujeres solitarias o vírgenes consagradas, aquellas que optaron por la vida religiosa. En ambas el referente es la mujer emancipada de la Europa ilustrada que defendía la igualdad entre hombres y mujeres para todo aquello que no concerniera a las diferencias naturales del sexo, las cuales sustentaban, entre otras cosas, las relaciones que se establecen entre estos, las oposiciones y por supuesto, los deberes de cada uno con el Estado y la sociedad.

5 Actualmente se prefiere que las mujeres ya tengan estudios de secundaria.
Lo que permite tal razonamiento son los sentidos asignados a la diferencia sexual, como "conjunto de normas que asignan a los cuerpos propiedades y lugares en lo social" (Rivera, 2006, p. 191). En una colección de material educativo elaborado por el equipo de Pastoral Vocacional de México y que se difundió por los países de América Central y el Caribe, señalan las hermanas escolapias: "Hay un hecho fundamental que es el sexo. Dios ha creado la humanidad sexuada. El sexo divide a la humanidad en hombres y mujeres; es un hecho: sexo femenino y sexo masculino" (Reflexiones vocacionales, 1998-2001, p. 32). Desde esta comprensión, se señalan características tanto biológicas como psíquicas que se consideran estrictamente femeninas o masculinas y que son a su vez complementarias entre sí: delicadeza, afectividad, emotividad, con un sentido de cuidado y defensa por la vida debido a la capacidad de engendrar la vida en lo definido como femenino; frente a fuerza, dureza, racionalidad, cálculo, en lo definido como masculino. Como afirma Butler (2010), tal diferencia organiza los cuerpos con base en dos posiciones opuestas y complementarias, con lo que se estabiliza el género - masculinidad/feminidad- dentro de una matriz heterosexual.

Las diferencias entre los sexos también sugieren que la naturaleza femenina ha de ser conducida y una de las vías será la educación ${ }^{6}$, que desde esta comprensión es la que posibilita el perfeccionamiento de las facultades superiores, entre ellas la espiritualidad. Esta última también se asume sexuada y aunque en cada caso se pueden presentar ciertas cualidades, hay una polaridad que termina siempre manifestándose de manera diferenciada en las operaciones espirituales de cada sexo: lo femenino es más intuitivo, sintético y místico; lo masculino por su parte es más racional, discursivo y analítico (Reflexiones vocacionales, 1998-2001, p. 33). La Europa de la razón como paradigma nos presenta una comprensión de hombre y mujer como categorías monolíticas y universales, que dan cuenta del grupo dominante como norma, donde el ciudadano moderno: hombre blanco y heterosexual, es el referente a partir de la cual se definen las mujeres (Lugones, 2008) ${ }^{7}$.

6 Se refiere aquí a una educación ilustrada y para las elites, no educación pública para el pueblo. Se ve aquí una apropiación de los planteamientos de Rosseau en torno a la educación (Emilio), pero tomando una clara distancia con sus concepciones en torno a la educación de las mujeres (Sofía).

7 Para el año 2012, a propósito de esta labor de promoción de la mujer, se reunieron en Roma escolapias de todos los países donde la congregación estaba presente en un seminario titulado "La espiritualidad de Madre Paula como pozo de agua viva". La madre Eunice Vélez de Colombia propuso un 
Cuadro 1.

\begin{tabular}{|c|c|}
\hline En la mujer, el hombre aprecia & En la mujer, al hombre le desagrada \\
\hline $\begin{array}{l}\text { El buen humor y el optimismo, la naturalidad y el tacto, } \\
\text { la inteligencia sin ostentación, la cultura sin pedantería, } \\
\text { la conversación atractiva y amena, la feminidad en todos } \\
\text { los momentos, que sepa escuchar con atención sin inte- } \\
\text { rrupción a cada instante, que lo adule discreta y oportu- } \\
\text { namente, que le muestre su admiración y confianza, que } \\
\text { se interese en sus problemas y actividades, que lo deje } \\
\text { sentirse un poco protector y sepa cuando mimarlo, que } \\
\text { sepa cuando dejarlo solo con sus pensamientos, que sepa } \\
\text { ser discreta con su pasado, que sea buena compañera y se } \\
\text { divierta con lo que a él le divierte, que ella se comporte } \\
\text { como una dama es decir con dignidad y decoro, que viva } \\
\text { su vocación al amor, que goce de la maternidad que Dios le } \\
\text { ha confiado, que sepa ser fiel sin límites. }\end{array}$ & $\begin{array}{l}\text { Deseo constante de exhibición, conversación excesiva, esce- } \\
\text { nas de celos, desconfianza, hacer reproches, las lágrimas } \\
\text { sentimentalistas, carácter violento, respuestas bruscas, } \\
\text { hipocresía, mentiras aunque sean pequeñas, coquetería } \\
\text { exagerada, indiscreción, exceso de frivolidad, deseo de lujo, } \\
\text { pedantería, la presunción o el orgullo exagerado, adoptar } \\
\text { poses infantiles o de vampiresa, que demuestre demasiada } \\
\text { cultura o independencia, que pregunte sistemáticamente } \\
\text { ¿de dónde vienes? ¿Qué hiciste? }\end{array}$ \\
\hline
\end{tabular}

Fuente. Equipo de Pastoral Vocacional Viceprovincia de México (1998-2001) (p. 39).

Cuando Monique Wittig ([1980] 2006) definió el pensamiento heterosexual, aludió a este como un referente ordenador de las relaciones humanas, fundamentalmente sostenido por la construcción social y política de la diferencia sexual ${ }^{8}$ que se impone como "interpretación totalizadora, como principio evidente, como un dato anterior a toda ciencia", que universaliza la producción de conceptos, leyes e individuos (p. 51). En este sentido, las representaciones de género cumplen una función normativa que va a excluir aquello que se escapa de las fronteras de lo que afirman y legitiman como feminidad y masculinidad, lo cual nos supuso preguntarnos ¿Quién o quiénes encarnan los límites de este pensamiento

acercamiento actualizado de esta misión: "Mirar un poco al pasado, al presente y al futuro de nuestra historia desde las coordenadas del siglo XIX y Xx [sic], con la intencionalidad de acercarnos a la realidad de la mujer en el contexto educativo español, sobre todo de Hispanoamericano [sic] y colombiano, permite confirmar que el ideal de Paula Montal es tan válido en la actualidad como lo fue en su época y que el tema de la mujer sigue siendo en todo tiempo y lugar una necesidad apremiante que requiere atención, aunque las circunstancias cambien el sujeto en su esencia, es decir, la mujer sigue marcada por una realidad que la pone en desventaja con el varón. A pesar de todo lo que supuestamente hemos evolucionado, en la mujer sigue existiendo el dolor del machismo, de la minusvaloración, de la utilización. La mujer como realidad es la gran víctima de la violencia, el maltrato, la postergación, el rechazo, la violación de sus derechos como persona y como mujer, el desprecio a sus valores femeninos que son valores diferentes a los valores oficiales propios del machismo, y justamente por ser diferentes son una oportunidad de cambio en cuanto que la mujer sea mujer y que los valores de lo femenino, cuestionen, transformen y dignifiquen el mundo" (Vélez, 2012).

8 Importante resaltar que si bien la autora se centra en la diferencia sexual, también hará referencia a lo largo de su planteamiento que al ejercicio de dominación subyace la construcción de cualquier diferencia, por ejemplo, la diferenciación que produce la racialización como fundamento del dominio. heterosexual? ¿Cómo se definen estos límites? En uno de los textos de formación, en la dimensión humana, encontramos un listado de características (cuadro 1).

Butler (2010) sostiene que si bien asumir o no una identidad femenina no es de ningún modo una elección o un gesto voluntario, tampoco es una imposición determinante. No obstante, obedece a convenciones sociales y sufrirá reacciones punitivas y reguladoras en caso de que la interpretación no se ajuste, escape a la norma o la rebase. Acogiendo este planteamiento podríamos suponer que en esta lista, no agradar al hombre es una de las sanciones reguladoras que sin excluir a aquella mujer, sí la van a situar como representación de lo impropio. La polaridad en que lo masculino es referente constitutivo de la feminidad nos lleva a suponer que quien no responde a este ideal ficcional es leída dentro del mismo marco de la heteronormatividad como carente de feminidad o como si habitara la incompletud. Esto, entre otras cosas, asegura la necesidad de educarla.

Las vírgenes consagradas, por su parte, son las esposas de Cristo y comparten cualidades con la mujer anteriormente descrita, como la alegría y el sentido del humor, el cuidado de los otros o la entrega con amor. El vínculo esponsal se puede observar en numerosas congregaciones femeninas, donde una serie de actividades, premisas, oficios, dan cuenta de la mujer de este matrimonio: ella tiene deberes con su marido, es sumisa, dispuesta, entregada, fiel, perteneciente a él, alegre y servicial. Todas estas cualidades son vehiculizadas por el sentimiento del amor, que vivido de esta manera es exclusivo de ciertas mujeres (Herrera y Ojeda, 2015).

Esta espiritualidad esponsal caracterizada por asumir una relación amorosa con Cristo como esposo parece ser producto de renovadas formas institucio- 
nales que se expresaron en agrupaciones más devocionales que doctrinales, como señala una escolapia en un seminario sobre espiritualidad de Madre Paula, realizado en Roma en el año 2012:

es una espiritualidad individualista en su concepción de la vida espiritual, aunque preocupada por el bien espiritual y material del prójimo, que intenta realizar generosamente; acepta la ascesis y la mortificación, reconociéndolas como caminos necesarios que nos conducen a Dios; es moralizante y afectiva más que doctrinal; conserva su distancia frente al mundo, cuyos valores negativos percibe como contrarios a sus propios principios." Ya que podemos deducir que la espiritualidad esponsal no es uno de los rasgos propios de la espiritualidad del siglo XIX, yo me atrevo a lanzar la hipótesis de que este rasgo explícito de lenguaje amoroso en relación a Cristo esposo pueda resultar una clara influencia de la figura de Santa Teresa de Jesús en la espiritualidad de la santa escolapia. (Giménez, 2012, p. 4)

En este y otros documentos de la congregación que abordan el tema, resulta interesante el uso de metáforas, figuras y símbolos en torno al noviazgo, la declaración de amor, los desposorios, el banquete de boda, la noche de bodas, la relación esponsal y la misión de engendrar vida. La intimidad con el esposo se vive desde la oración, que es el momento en que se está a solas con él; de ahí que sea una de las técnicas corporales que mayor preparación y exigencias requieran: cuidado de los espacios y ritmos orantes, consecución del silencio interior y exterior, aprendizaje de lectura orante de la Biblia, examen de conciencia diario, escucha y acogida de la palabra de Dios (Allegre et al., 1983).

Con respecto a las regulaciones en esta feminidad, la virgen consagrada enfrenta dos posiciones, como esposa de Cristo a quien le concierne lo referido a las virtudes femeninas que requiere su vínculo, y como religiosa, aquellos impedimentos para la vivencia de su vocación: quienes que no logran encontrarse con ellas mismas, dificultades para establecer distancias y renuncias con el mundo exterior, incapacidad de permanecer en el silencio que permite alcanzar la verdad interior, entre otras. Similar a la función reguladora que opera para la mujer esposa, la escolapia que no logra alcanzar el ideal no es excluida; por el contrario, en estos casos, la comunidad igualmente acompaña y orienta a la religiosa a que se encuentre como mujer laica, también evangelizadora y con los deberes ya mencionados con la sociedad.

Es importante resaltar que estos mandatos no pueden asumirse de modos fijos o estables. El mismo ideal regulatorio alberga la ambigüedad que se manifiesta en la esposa/virgen: mujer activa pero depen- diente, espiritual y austera, pero no cuestionadora del capitalismo como forma de vida, esposa y dadora de vida, cuyo cuerpo no encarna el precepto reproductivo. Incoherencia, contradicción, discontinuidad, aquello por lo cual un cuerpo se sabe humano. A pesar de esto y aunque no serán objeto de profundización en este análisis, encontramos figuras cuya exclusión daría cuenta de otredades amenazantes y no tematizadas por este marco e inteligibilidad, entre las que queremos destacar: aquellas que presentan defectos físicos, aquellas sobre quienes recae un pasado vergonzante (Constituciones, [1853] 2004, p. 44) y aquellas influenciadas por "las corrientes extremistas del feminismo" (Congregación para los Institutos de Vida Consagrada y las Sociedades de Vida Apostólica, 1994).

\section{El cuerpo de la escolapia: mujer, maestra y religiosa}

La Escolapia de ojos contemplativos se levanta al alba y agradecida espera la lluvia de gracias que fecundará toda su jornada.

Curso de formación, 2004

5:00 a.m. Levantada; 5:30 a.m. Oración personal; 6:00 a.m. Misa con laudes; 6:30 a.m. Desayuno; 7:00 a.m. - 12:20 p.m. clases en el colegio; 12:30 p.m. Almuerzo; 1:00 p.m. - 2:39 p.m. Clases o trabajo en el colegio; 3:00 p.m. - 6:15 p.m. Trabajo personal bien sea preparando clases u oración; 6:20 p.m. Acto mariano y vísperas; 7:00 p.m. Cena; 8:00 p.m. - 9:00 p.m. recreo comunitario.

(Día corriente de una escolapia que no esté realizando estudios. Conversación con novicia)

El convento, nombre con que las escolapias en formación y personas no pertenecientes a la congregación llaman a la casa de noviciado, funciona como un espacio de encierro y recogimiento. Separa a las mujeres que se inician en la vida religiosa de sus casas y familias, construyendo un adentro singular caracterizado por tener una organización propia que marca los tiempos, los espacios, las actividades que allí tienen lugar y las responsabilidades de los sujetos implicados. Como señaló Foucault, instituciones como esta tendrán entre otras, la función de "controlar, formar, valorizar, según un determinado sistema, el cuerpo del individuo" (1986, p. 133).

En este convento de segunda mitad de siglo xx, en el contexto latinoamericano brevemente anunciado en el apartado anterior y donde se forman mujeres, maestras y religiosas, confluyen dos formas de poder que toman por objeto el cuerpo: el ascetismo cris- 
tiano y el poder disciplinario. Allí existen espacios definidos para cada actividad que se realice, sea la oración, el descanso, tomar los alimentos, estudiar, etc. En esta distribución se consideran también los intercambios con el exterior puesto que la formación de comunidades dedicadas a la actividad apostólica requiere de la interacción con otros: la Conferencia de Religiosos de Colombia (CRC), donde reciben algunas clases del campo teológico; las escuelas donde enseñan o apoyan alguna actividad educativa; las comunidades donde se realiza la misión evangelizadora; las instituciones de educación superior donde hacen sus estudios, entre otros.

En esta última parte nos focalizaremos en algunas prácticas que tienen lugar en el convento y dan como resultado la ficción somática que llamamos cuerpo. Acogemos a Preciado para entender que "no hay cuerpo sino un conjunto heterogéneo, siempre en ruptura, de categorías de conocimiento, sistemas de representación, técnicas de gobierno, que luchan por producir modos de subjetivación" (2014). En este espacio singular surge lo que aquí llamaremos provisionalmente el cuerpo de la escolapia; cuerpo que ejecuta -y se hace cuerpo- a través de prácticas que construyen la experiencia religiosa, personal y comunitaria; cuerpo dócil, disciplinado, propio de las instituciones de encierro; cuerpo que también se fuga, se quiebra, se deshace, en la fragilidad misma que lo constituye.

Estas prácticas podemos encontrarlas a modo de prescripciones, por ejemplo aquellas orientadas al orden y la limpieza tanto personal como comunitaria. En una hoja pegada en la nevera de la cocina del convento, se exponen con resaltados y subrayados las tareas que realizan la persona responsable de la cocina y el aseo y la religiosa de apoyo:

\footnotetext{
Limpieza de la cocina en todas sus dependencias (piso, armarios, techo, ventanas, campana, mesones, estufa, filtro, nevera, congelador, despensa); aseo de los comedores incluyendo todos sus componentes; aseo de las salas de la entrada, la sala y el pasillo; lavar el lavadero y piso cada semana; limpieza de los salones de convivencias a la mañana siguiente de ser usados. Dejarlos listos con todo lo necesario: papel higiénico, jabón, toallas, bolsas puestas en las papeleras y las canecas.
}

No obstante, estas tareas no pueden hacerse de cualquier manera. De acuerdo con Mauss (1979) las técnicas corporales son actos tradicionales y eficaces que se tornan mecánicos, se consideran "naturales", cuyo instrumento de ejecución y apropiación es el cuerpo y se ajustan en procesos de transmisión, imitación y educación. Le Breton retoma este concepto y las define como "gestos codificados para obtener una eficacia práctica o simbólica, se trata de modalidades de acción, de secuencias de gestos, de sincronías musculares que se suceden para obtener una finalidad precisa" (2002, p. 41). En el caso de la limpieza de los espacios del convento, se indica puntualmente:

[...] lavar las toallas de la cocina todos los días, preferiblemente con agua caliente. Lavar los baños de abajo todos los días. El de arriba cada tres. Cada 8 días con desmanchador. Echar los productos biológicos en inodoros y sifones de la cocina... [énfasis en el original]

Para el cuidado de los alimentos se recomienda "Cuidar que las frutas y verduras no se dañen" y con un resaltado específico: "Dar vuelta a las frutas" [énfasis en el original].

Lo que observamos es que a través de estas se produce una cultura corporal determinada, que sirve de marco y referente en el que dichos gestos, actos, modos de usar el cuerpo, etc. son inteligibles, teniendo por ello un poder no solo normativo sino ante todo productivo. Atendiendo esto, queremos destacar entre las más importantes:

Técnicas orientadas a la purificación del cuerpo, referidas a prácticas de alimentación sana y equilibrada bajo el enunciado del cuidado de la salud $^{9}$, que buscan además entrenar en la oración, la renuncia ${ }^{10}$, la realización de actividades físicas y el deporte ${ }^{11}$.

Técnicas orientadas al autoconocimiento, enseñadas a través de ejercicios que buscan que la escolapia viva una relación de cercanía con sus emociones y se haga cargo de su propia transformación. La fundamentación de estas articula sin conflicto, principios y autores del enfoque psico-

9 El ayuno como estrategia de limpieza y contención trasladable a otros deseos e impulsos: “'Los extremos se tocan', este es un principio directivo. Tan perjudicial es comer demasiado como comer excesivamente poco, en los dos casos podemos caer en la apatía. Si el ayuno es una práctica habitual de nuestra vida nuestros cuerpos estarán afinados para el trabajo ulterior de la mente" (Curso de formación, 2004, p. 41).

10 "Las cosas pueden ser un sustito de Dios si les entregamos el corazón y entonces se convierten en ídolos. Necesito pocas cosas y estas muy poco, decía San Francisco. La acumulación de cosas en la habitación o despacho distorsionan la armonía del espíritu. Un ejercicio muy saludable es ir seleccionando mis cosas: no tener cosas en exceso, no elegir cosas de demasiada calidad, evitar la codicia y la avaricia, abstenernos de envidiar las cosas que tienen los demás" (Pedagogía de la oración, 2004, p. 43).

11 Forma parte del proyecto personal anual de cada formanda, y no están previamente establecidas. En fotografías de su archivo se observan hermanas jugando fútbol o bailando. 
lógico humanista con el análisis experimental del comportamiento ${ }^{12}$ y procesos como la percepción con la motivación o la personalidad, abordando así instancias como autoestima, autoconcepto, autoevaluación y autorrespeto.

Técnicas orientadas a la formación de hábitos, donde ubicamos aquellas relacionadas con la formación académica, pastoral y teológica, donde se educa el cuerpo en unas maneras de leer ${ }^{13}$, de seguir rutinas individuales, de participar en encuentros de comunidad, entre otras.

Técnicas orientadas a entrar en contacto con Dios, a través del aprendizaje y la práctica de la oración ${ }^{14}$.

Hasta aquí tenemos un cuerpo religioso y consagrado, no muy diferente a otras congregaciones femeninas o masculinas. No obstante, estos cuerpos, como hemos mencionado, también son producidos desde un referente de diferenciación sexual. Al respecto, seguimos a Butler (2010) cuando afirma que el sexo "es una práctica reguladora que produce los cuerpos que gobierna, es decir, cuya fuerza reguladora se

12 "El autoconocimiento es conocer las partes que componen el yo, cuáles son sus manifestaciones, necesidades y habilidades; los papeles que vive el individuo y a través de los cuales es; conocer por qué y cómo se actúa y se siente. Al conocer todos sus elementos, que desde luego no funcionan por separado sino que se entrelazan para apoyarse uno al otro, el individuo logrará tener una personalidad fuerte y unificada; si una de estas partes funciona de manera deficiente las otras se verán afectadas y su personalidad será débil y dividida, con sentimientos de deficiencia y devaluación" (Equipo de Pastoral Vocacional Viceprovincia de México, 1998-2001, p. 10). Se proponen ejercicios que implican dibujar, escribir y responder preguntas reflexivas; también lecturas para la reflexión.

13 Las fases de la Lectio Divina son: 1. lectura serena que es pausada, hecha con calma y entonación. 2. Lectura con silencios más interiorizante con pausas en párrafos o palabras que llamen la atención, con ellos se venera y acoge la palabra y se interioriza. 3. Lectura con acentos, se dedica especial énfasis a párrafos o frases que llamen la atención. 4. Lectura dialogada, se entra en diálogo con las palabras escogidas (Pedagogía de la oración, 2004, p. 70).

14 "El cuerpo guarda la memoria de la vida y el cuerpo nos ayuda mucho en el proceso de oración. A través de nuestra realidad corporal llegamos al autoconocimiento, esto nos ayuda en el crecimiento personal y este crecimiento fundamenta y vigoriza nuestra experiencia de Dios". Existen manuales que prescriben una serie de técnicas corporales orientadas a enseñar y educar en la oración. Parten de una comprensión del cuerpo como medio para el encuentro con Dios, que se va perfeccionando, similar a la que fundamenta la pedagogía católica de primera mitad de siglo xx: toma de conciencia de la respiración, integración de sonidos, expresión corporal, posturas de los brazos, manos, formas y objetos a los que van dirigidas las miradas, maneras de arrodillarse, entre otras (Pedagogía de la oración, 2004). manifiesta como una especie de poder productivo, el poder de producir - demarcar, circunscribir, diferenciar- los cuerpos que controla" (p. 18).

La materialización del sexo se da por medio de prácticas reiterativas que surgen en marcos históricos y culturales; hacen viables los cuerpos, y se expresan y actualizan permanentemente en marcos normativos y simbólicos que sustentan las construcciones identitarias hegemónicas de hombre-mujer. En este orden, lo que queremos exponer para finalizar es que el cuerpo escolapio se hace cuerpo sexuado, a través de dos potentes dispositivos de engenerización: $L a$ heterosexualización de la experiencia religiosa que abordamos y la enseñanza, oficio asumido como extensión de la maternidad. No obstante, hay también una fuga expresada como ambigüedad que tratamos en las reflexiones finales y que insinúa, a manera de provocación, que este cuerpo también puede leerse como un cuerpo inapropiable.

\section{Enseñar a las niñas piedad, labores de mano y letras}

Desde su misión educadora, permanece en la escolapia el enunciado de la mujer como salvadora de la familia, que es el núcleo de la sociedad; una tarea que inicia en el ámbito privado del hogar y que tendrá incidencia en lo social. Se trata de la familia heterosexual, fundamentada en un contrato social que es indefectiblemente un contrato sexual (Pateman, 1995). La familia es una alianza con roles muy bien definidos y complementarios, una relación de poder y de producción de cuerpos y subjetividades, cuyo referente es la diferencia sexual.

Las mujeres en formación religiosa asumen esta diferenciación para la comprensión de unas características psicológicas femeninas como raíl de trabajo en su dimensión humana y en la de sus alumnas. Esto a su vez se refleja en el oficio de la enseñanza, asumida como apostolado que requiere de ellas tres características: caridad, con que se presta un servicio desinteresado y de entrega completa; paciencia en el proceso educativo; y María como modelo espiritual y apostólico (Madres escolapias, 1983). La labor educativa se ejecuta con amor y entrega, que son cualidades propiamente femeninas, y acerca a las mujeres al cumplimiento de la responsabilidad adquirida en el proyecto moderno educador: moralizar a la sociedad (Herrera y Ojeda, en proceso de edición). En este sentido, la enseñanza es un dispositivo a través del cual las escolapias se feminizan y a su vez feminizan a las niñas que acompañan: 
Nuestras Constituciones de 1981 lo formulan en estos términos: "Esta misión educadora tiene como fin que nuestras alumnas amen y busquen la verdad, se formen para llegar a ser fermento salvador de la familia - fundamento de la sociedad-y, como auténticas colaboradoras del reino de Dios, participen en la construcción de un mundo más justo y más humano". (Constituciones, 1981, p. 45, I. 13 y ss.)

\section{Reflexiones finales}

Nos hemos interesado por el convento como un espacio de producción de feminidades y cuerpos. El análisis se ha centrado en una congregación religiosa femenina en Colombia, desde una mirada de historia reciente. Hemos identificado dos representaciones: las madres-esposas y las vírgenes consagradas, que aunque diferentes son inteligibles a través de una matriz heteronormativa. Sus cuerpos responden a la imbricación de técnicas corporales tanto del ascetismo cristiano como del poder disciplinario, que se expresan en gestos, contornos, modos de usarlo, de cuidarlo, de ejercitarlo, que los hacen dóciles y útiles, cuya engenerización tiene lugar a través de los dispositivos de la enseñanza y la heterosexualización de la experiencia religiosa.

Desde el referente blanco europeo, las mujeres religiosas sostienen una relación con Dios que se hace viable mediante el vínculo esponsal, que fundamenta la conformación de la familia moderna: burguesa, monogámica y heterosexual, protegida por el Estado y núcleo de la sociedad. Esta relación produce y es producida en la definición de roles y funciones para cada uno de sus integrantes, para el caso de las mujeres la función es la reproductiva. Al respecto, Preciado expone una genealogía política del útero y plantea que este:

Aparece en un momento histórico dado, en un campo epistémico y en un conjunto específico de relaciones de saber-poder, hasta convertirse históricamente en un órgano encarnado, produciendo la ficción política viva de la madre como cuerpo reproductivo, eso que yo vengo llamando la madre biopolítica, es decir el cuerpo femenino pensado como máquina de reproducción nacional. (2014)

Siguiendo a Preciado en conversación con Forcades (2014), la monja, la lesbiana y la prostituta no entran en los ritos sociales de producción heterosexual, ya que ocupan una posición excéntrica. Sin embargo, cuando se trata de la religiosa también nos encontramos frente a una ambigüedad: su feminidad, su construcción de identidad como mujer, maestra y religiosa, su cuerpo sexuado y hasta su singular sexualidad, están enteramente plagados de modernidad. Pero sus úteros tendrán una relación particular en el cuerpo del Estado moderno, que es desde su surgimiento androcéntrico y patriarcal (Pateman, 1995).

El tránsito por el espacio religioso configura $-\mathrm{y}$ reconfigura - ambiguamente un determinado régimen de vida (una dieta o régimen físico y moral en el sentido etimológico) que excede los procesos de generización y sexualización instalando y re-instalando modos de ser y estar en el mundo ${ }^{15}$. La esposa de Cristo es una figura que surge en el misticismo de mujeres de vida contemplativa ${ }^{16}$, cuyos encuentros con su amado sugerían otro tipo de sensibilidades y corporalidades, que incluso en no pocas ocasiones fueron censurados. Esposa sumisa, obediente, enamorada, incondicional, pero que se resiste a la reproducción, cuyos úteros biopolíticos como sugieren Preciado y Forcades, son inutilizados de manera voluntaria. En este sentido nos preguntamos $i$ es la monja una mujer? Si, como hemos visto, las representaciones tienen una función normativa que se sitúan como referente y a su vez lo actualizan, podríamos entonces suponer que la monja desafía el régimen heterosexual, habitando el intersticio.

\section{Referencias}

Butler, J. (2001). El género en disputa. El feminismo y la subversión de la identidad. México: Paidós.

Butler, J. (2010). Cuerpos que importan. Sobre los límites materiales y discursivos del "sexo". Buenos Aires: Paidós.

Corbin, A.; Courtine, J. y Vigarello, G. (2005). Historia del cuerpo. De la Revolución francesa a la Gran Guerra (tomo 2). Madrid: Taurus.

15 El término dieta proviene del griego diaita, que significa 'un modo de vida'. Como regulación de la vida, posee el significado médico más específico de comer de acuerdo con reglas prescritas. Existe un segundo significado de dieta, que es una' asamblea política de príncipes con propósitos de legislación y administración. Este segundo significado proviene del vocablo francés dies o día, ya que las dietas políticas se reunían en días determinados y eran, por tanto, reguladas por un calendario. La dieta es o bien una regulación del cuerpo individual, o bien una regulación del cuerpo político. El término régimen tiene también esta doble implicación. Se deriva de regere o 'gobernar' y, como término médico, alude a un sistema terapéutico, que engloba de forma característica la dieta; pero el régimen es asimismo un sistema de gobierno, como en regimentación o "régimen". Podemos ver, entonces, que tanto la dieta como el régimen se aplican al gobierno del cuerpo y al gobierno de los ciudadanos. Este argumento etimológico refuerza aún más el argumento de que las metáforas de la salud y la enfermedad (sexuales, morales, políticas, etc.) constituyen metáforas persistentes de la organización social" (Turner, 1989, p. 205).

16 Santa Teresa será aquella figura que inspire a la fundadora Paula Montal, y referente de lectura de las escolapias aún vigente. 
Foucault, M. (1986). La verdad y las formas jurídicas. México: Gedisa.

Herrera, X. y Ojeda, C. (en proceso de edición). El amor y aquello de ser mujer: aproximaciones a la configuración de lo femenino en la escuela colombiana (XIX-XX). Actualidades Pedagógicas.

Jiménez, M. (2015). La educación de las mujeres populares bogotanas 1984-1995. Trabajo de grado (tesis de maestría en Educación). Universidad Pedagógica Nacional, Bogotá, Colombia.

Le Breton, D. (2002). Sociología del cuerpo. Buenos Aires: Nueva Visión.

Lugones, M. (2008). Colonialidad y género. Tábula Rasa, $9,73-101$

Mauss, M. (1979). Sociología y antropología. Madrid: Tecnos.

Pateman, C. (1995). El contrato sexual. Universidad Autónoma Metropolitana-Iztapalapa, México: Anthropos.

Preciado, B. (2014, mayo). Ponencia presentada en: "Cuerpos inapropiables propiedad, expropiación y políticas de lo 'común'” [Audio]. Recuperado de http://www.macba.cat/es/ audio-beatriz-preciado-cuerpos-inapropiables

Preciado, B. y Forcades, T. Encarnar disidencias. Entrevista con Andrea Valdés. Recuperado de https://teresaforcades.files.wordpress.com/2014/08/encarnar-disidencias.pdf21994_fraternal-life-in-community_sp.html

Ramírez, M. (2003). Las mujeres y la acción social en Colombia, contextos de contradicciones. Boletín Americanista, 53, 152-167.

Rivera, C. (2006). Una historia política de la diferencia sexual. En M. Viveros, C. Rivera y M. Rodríguez (comps.). De mujeres, hombres y otras ficciones... Género y sexualidad en América Latina. Bogotá: Universidad Nacional.

Scott, J. (2011). Género: ¿Todavía una categoría útil para el análisis? La Manzana de la Discordia, 6, 95-101.

Turner, B. (1989). El cuerpo y la sociedad. Exploraciones en teoría social. México: Fondo de Cultura Económica.

Wittig, M. (2006). El pensamiento heterosexual y otros ensayos. Madrid: Egales.

\section{Fuentes primarias}

Alegre, E.; Albiñana, M.; Costanera, M.; Labarta, L.; Micip, C. y Pérez, D. -Religiosas de las Escuelas Pías- (2008). Tradición pedagógica de las religiosas de las Escuelas Pías (Escolapias). Pensamiento Educativo, 42, 159-180.
Alegre, E.; Sesma, C.; Armendaz, C. y Costa-Jusa, R. Religiosas de las Escuelas Pías (1983). La formación inicial y permanente de las Escolapias. España: Talleres Gráficos Edelvives,

Butler, J. (1998). Actos performativos y constitución del género: un ensayo sobre fenomenología y teoría feminista (M. Lourties, trad.). Debate Feminista, 18, 296-314. Recuperado de http://caosmosis.acracia.net/ wp-content/uploads/2008/07/judith-butleractosperformativos-y-constitucion-de-genero.pdf

Código de Derecho Canónico. Roma (1983).

Congregación General Escolapias. (2015). Formación inicial y permanente de la escolapia. Roma.

Congregación para los Institutos de Vida Consagrada y las Sociedades de Vida Apostólica. (1994). La vida fraterna en comunidad Congregavit nos in unum Christi amor. Roma. http://www.vatican.va/ roman_curia/congregations/ccscrlife/documents/ rc_con_ccscrlife_doc_020

Constituciones de la Congregación de las Hijas de María dedicadas á las enseñanzas de las niñas conforme á las que escribió para los maestros de las escuelas pías su fundador San José de Calasanz. ([1853] 2004). Barcelona: Imprenta de Juan Gaspar.

Decreto Perfectae caritatis. Sobre la adecuada renovación de la vida religiosa. 28 de octubre de 1965. Roma

Equipo de Pastoral Vocacional Viceprovincia de México (1998-2001). Reflexiones vocacionales. Dimensión humana.

Giménez, I. (2012). La dimensión esponsal y la vida de oración en Santa Paula Montal. Ponencia presentada en el Seminario "La espiritualidad de Madre Paula como pozo de agua viva”. Roma, Italia.

Madres Escolapias (1983). Libro de formación. Documento de experimentación. Capítulo General, Roma.

Pedagogía de la oración. Curso de formadoras. (2004). Documento institucional. Arenys de Mar.

Scott, J. (1999). El género: una categoría útil para el análisis histórico. En: Navarro y Stimpson (comps.). Sexualidad, género y roles sexuales (pp. 37-76). México: Fondo de Cultura Económica.

Vélez, M. (2012). La promoción de la mujer, esencia de la espiritualidad escolapia. Ponencia presentada en el Seminario "La espiritualidad de Madre Paula como pozo de agua viva”. Roma, Italia. 